\title{
Adrenaline overdose in pediatric anaphylaxis: a case report
}

\author{
Pui Yi Lily Liew ${ }^{1,2^{*}}$ (D) and John Andrew Craven ${ }^{1}$
}

\begin{abstract}
Background: Adrenaline is the standard treatment for anaphylaxis but appropriate administration remains challenging, and iatrogenic overdose is easily overlooked. Despite the established importance of pediatric blood pressure measurement, its use remains inconsistent in clinical practice.

Case presentation: We report a case of adrenaline overdose in a 9-year-old white boy with anaphylaxis, where signs of adrenaline overdose were indistinguishable from progressive shock until blood pressure measurement was taken.

Conclusions: The consequences of under-dosing adrenaline in anaphylaxis are well-recognized, but the converse is less so. Blood pressure measurement should be a routine part of pediatric assessment as it is key to differentiating adrenaline overdose from anaphylactic shock.
\end{abstract}

Keywords: Pediatric, Children, Anaphylaxis, Adrenaline, Epinephrine, Overdose, Blood pressure, Case report

\section{Background}

Anaphylaxis, the most severe form of allergic reaction, is a life-threatening multi-systemic inflammatory process $[1,2]$ mediated by immunoglobulin E (IgE) [3]. The incidence of anaphylaxis in the pediatric group aged 5 to 14 has shown a marked upwards trend since $1990[4,5]$, and with the rapid onset and progression of the disease process, prompt action is key to successful management. Adrenaline is the recommended first line treatment in Australia, either through an autoinjector (commonly used in the community) or adrenaline ampoules and syringes [2]. Its use can be challenging due to nonintuitive dilution and dosing - particularly in the pediatric population.

We describe a case of adrenaline overdose in a child experiencing anaphylaxis, and discuss the role of blood pressure to differentiate progression of anaphylaxis symptoms from adrenaline toxicity.

\section{Case presentation}

A 9-year-old white boy (weight $32 \mathrm{~kg}$ ), known to have multiple allergies, asthma, and a history of anaphylaxis

\footnotetext{
* Correspondence: Lily.P.Liew@gmail.com

${ }^{1}$ Department of Emergency Medicine, Flinders Medical Centre, Flinders Drive, Bedford Park, 5042 Adelaide, Australia

${ }^{2}$ Present address: Department of Obstetrics and Gynaecology, Monash Health, Casey Hospital, 62-70 Kangan Drive, Berwick 3806, Victoria, Australia
}

to dairy products and nuts, developed generalized body rash, dyspnea, and confusion after inadvertently ingesting a school meal containing a dairy product. He was promptly given $300 \mu \mathrm{g}$ intramuscular adrenaline via a fixed-dose autoinjector, as well as $600 \mu \mathrm{g}$ of salbutamol via metered-dose inhaler (six puffs) by his teacher in the community.

Upon ambulance arrival, he was drowsy, cyanosed, and had marked generalized body swelling. Observations suggested a shocked state: heart rate 120 beats/minute, respiratory rate 40 breaths/minute, air oxygen saturation 85 to $90 \%$, loud respiratory wheeze, use of accessory muscles, and impalpable peripheral pulses. Further adrenaline was administered $300 \mu \mathrm{g}$ intramuscularly without significant improvement, and this was followed by a bolus of $25 \mu \mathrm{g}$ adrenaline administered intravenously. Twenty minutes into the event, on the presumption of refractory anaphylactic shock, an intravenous adrenaline infusion was commenced at $10 \mu \mathrm{g}$ per minute. His blood pressure was not measured during the event or on the journey to the hospital.

In our emergency department, he was extremely agitated with repeated vomiting, but only had minimal respiratory distress. Oxygen saturation was difficult to record due to poor peripheral perfusion and clamminess, despite a blood pressure of $207 / 187 \mathrm{mmHg}$ and heart rate of 160 beats/minute. Adrenaline toxicity was 
suspected and the adrenaline infusion was immediately ceased. He also received two separate doses of $2 \mathrm{mg}$ intravenously administered ondansetron for the vomiting with little effect. Serial 12-lead electrocardiograms showed sinus tachycardia without other changes, and a normal chest X-ray excluded other causes.

Within 30 minutes his blood pressure returned to normal and he developed further respiratory symptoms (wheeze and dyspnea). The rapid improvement in his blood pressure, agitation, and vomiting following cessation of the adrenaline infusion supported the diagnosis of adrenaline overdose. In view of his asthma, he was given intravenously administered hydrocortisone and rescue nebulizers (salbutamol and ipratropium) to control his respiratory symptoms. He was admitted to our hospital, observed for 24 hours and discharged home with no further sequelae.

\section{Discussion}

This case highlights adrenaline overdose, an iatrogenic complication rarely reported in the pediatric population, as a potential pitfall in the management of pediatric anaphylaxis. While delaying and under-dosing adrenaline in anaphylaxis is widely recognized as detrimental, one should remain vigilant for adrenaline overdose because the risk of adverse effects, such as ventricular arrhythmias, hypertensive crises, pulmonary edema, and associated mortality [1] is significant. Avoiding overdose in anaphylaxis requires careful attention to the administration of adrenaline, guided by the clinical status and vital signs of the patient.

Early recognition is pivotal in managing anaphylaxis. Children commonly demonstrate symptoms from one or more of the following systems: cutaneous (80 to 90\%), respiratory $(70 \%)$, gastrointestinal tract $(45 \%)$, cardiovascular (45\%), and central nervous (15\%) [1]. Once anaphylaxis is diagnosed or suspected, adrenaline is the first line treatment $[1,2]$. Australasian guidelines generally recommend administration of $10 \mu \mathrm{g} / \mathrm{kg}$ (up to $500 \mu \mathrm{g}$ ) of 1:1000 adrenaline as an intramuscular injection into the lateral thigh, repeated after 5 minutes if required $[1,2,6]$. When an adrenaline autoinjector is used, a $150 \mu \mathrm{g}$ device is prescribed for children age 1 to 5 (approximately 10 to $20 \mathrm{~kg}$ ) and $300 \mu \mathrm{g}$ for children age 5 and above [2]. If the symptoms of anaphylaxis remain refractory, an intravenously administered adrenaline infusion can be started at the rate of 0.05 to $1 \mu \mathrm{g} / \mathrm{kg}$ per minute after careful consideration and consultation with emergency care specialists $[2,6]$.

Intramuscular injection is the standard route of administration. Skeletal muscle has an abundant supply of blood vessels and adrenaline is rapidly absorbed into the blood circulation $[1,2]$ but the risk of overdose and side effects are far lower compared with intravenously administered bolus or infusion. Adrenaline administered intravenously should only be administered in anaphylaxis if there is failure to respond to repeated intramuscular doses, or there is imminent or actual cardiorespiratory arrest [2, 6-8]. Other routes of administration are less reliable given the unpredictable absorption $[9,10]$.

Monitoring pediatric vital signs can sometimes be challenging. Blood pressure has always been recognized as a vital part of pediatric assessment but routine measurement remains inconsistent $[11,12]$. In Australia, blood pressure measurement is recommended in the assessment of anaphylaxis in all age groups $[2,3,6,8]$ as it is the prime differentiator between anaphylactic shock and adrenaline overdose, as well as being an essential guide to anaphylaxis progression and need for further adrenaline dosing. Other manifestations of adrenaline toxicity such as tachycardia, palpitations, dyspnea, cold peripheries, agitation, and pallor [13] could be mistaken for worsening anaphylaxis, and further adrenaline may be incorrectly administered.

In cases of anaphylaxis where there is no apparent improvement with repeated adrenaline dosing, other differential diagnoses need be considered and/or further management needs to be initiated. Intravenously administered volume expansion should always be given in anaphylactic shock with repeated boluses of $20 \mathrm{~mL} / \mathrm{kg}$ normal saline. Bronchodilators can be considered adjuncts in children with respiratory distress or a known history of asthma. Current evidence suggests no proven benefit for glucocorticoids or antihistamines in managing anaphylaxis $[1,6]$.

\section{Conclusions}

Prompt adrenaline administration remains the cornerstone of managing anaphylaxis in the pediatric population; however, like all therapies it needs to be administered judiciously and its effect assessed to ensure correct dosing. In episodes of anaphylactic shock, blood pressure will provide a guide to the effectiveness of treatment and allows shock to be differentiated from adrenaline overdose.

\section{Acknowledgements \\ Not applicable. \\ Funding \\ Not applicable. \\ Availability of data and materials \\ Not applicable. \\ Authors' contributions \\ Both authors have been involved in the preparation of the manuscript and take public responsibility for the content. The preparation of this case report is in keeping with the CARE guidelines (2016 update). Both authors read and} approved the final manuscript.

Competing interests

The authors declare that they have no competing interests. 


\section{Consent for publication}

Written informed consent was obtained from the patient's legal guardian(s) for publication of this case report and any accompanying images. A copy of the written consent is available for review by the Editor-in-Chief of this journal.

\section{Ethics approval and consent to participate}

Informed consent for participation was taken retrospectively. Ethics review was not sought because the case report met criteria for exemption from such review according to the Southern Adelaide Clinical Human Research Ethics Committee policy (that is, the work is of "negligible risk").

\section{Publisher's Note}

Springer Nature remains neutral with regard to jurisdictional claims in published maps and institutional affiliations.

Received: 2 April 2017 Accepted: 10 April 2017

Published online: 08 May 2017

\section{References}

1. Simons FE, Ardusso LRF, Bilò MB, et al. World Allergy Organization guidelines for the assessment and management of anaphylaxis. World Allergy Organ J. 2011;4(2):13-37.

2. Australian Society of Clinical Immunology and Allergy. Guidelines: ADVANCED acute management of anaphylaxis. 2016. https://www.allergy.org.au/healthprofessionals. Accessed 20 Apr 2017.

3. Kirkbright SJ, Brown SGA. Anaphylaxis: recognition and management. Aust Fam Physician. 2012;41(6):366-70.

4. Mullins RJ, Dear KB, Tang ML. Time trends in Australian hospital anaphylaxis admissions in 1998-1999 to 2011-2012. J Allergy Clin Immunol. 2015;136(2): 367-75.

5. Liew WK, Williamson E, Tang MI. Anaphylaxis fatalities and admissions in Australia. J Allergy Clin Immunol. 2009;123:434-42.

6. Royal Children's Hospital, Melbourne, Australia. Clinical practice guideline on Anaphylaxis. 2015. http://www.rch.org.au/clinicalguide/guideline_index/ Anaphylaxis/. Accessed 20 Apr 2017.

7. Campbell RL, Bellolio MF, Knutson BD, et al. Epinephrine in anaphylaxis: higher risk of cardiovascular complications and overdose after administration of intravenous bolus epinephrine compared with intramuscular epinephrine. J Allergy Clin Immunol Pract. 2015;3(1):76-80.

8. Advanced Life Support Group. Advanced Paediatric Life Support: The Practical Approach, Australia and New Zealand. 5th ed. Australia: Wiley-Blackwell; 2012.

9. Simons FE. First-aid treatment of anaphylaxis to food: Focus on epinephrine. J Allergy Clin Immunol. 2004;113:837-44.

10. Simons FE, Roberts JR, Gu X, et al. Epinephrine absorption in children with history of anaphylaxis. J Allergy Clin Immunol. 1998;101(1):33-7.

11. Bird C, Michie C. Measuring blood pressure in children. BMJ. 2008:336:1321

12. Gilhotra $Y$, Willis F. Blood pressure measurements on children in the emergency department. Emerg Med Australas. 2006:18(2):148-54.

13. Aspen Pharmacare Australia Pty Ltd. ASPEN Adrenaline Injection: product information. 2010. Retrieved from https://www.ebs.tga.gov.au/ebs/picmi/ picmirepository.nsf/PICMI. Accessed 20 Apr 2017.

\section{Submit your next manuscript to BioMed Central and we will help you at every step:}

- We accept pre-submission inquiries

- Our selector tool helps you to find the most relevant journal

- We provide round the clock customer support

- Convenient online submission

- Thorough peer review

- Inclusion in PubMed and all major indexing services

- Maximum visibility for your research

Submit your manuscript at www.biomedcentral.com/submit 